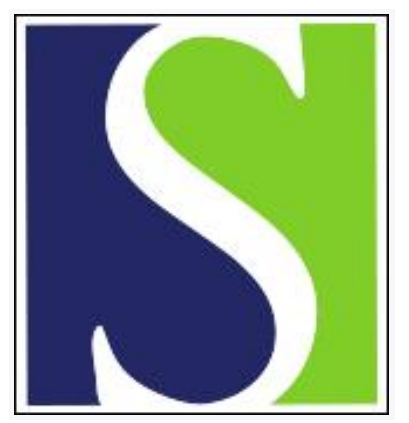

Scand J Work Environ Health 2003;29(3):206-215

https://doi.org/10.5271/sjweh.723

Issue date: Jun 2003

Lower socioeconomic status among men in relation to the association between job strain and blood pressure

by Landsbergis PA, Schnall PL, Pickering TG, Warren K, Schwartz JE

Affiliation: Department of Community and Preventive Medicine, Mount Sinai School of Medicine, PO Box 1043, One Gustave L levy Place, New York, NY 10029-6574, United States. paul.landbergis@mssm.edu

Refers to the following text of the Journal: 1998;24(5):334-343

The following articles refer to this text: SJWEH Supplements 2008;(6):22-32; SJWEH Supplements 2008;(6):41-51; 2014;40(2):109-132; 2019;45(2):209-210

Key terms: blood pressure; hypertension; job strain; job stress; man; social class; socioeconomic status

This article in PubMed: www.ncbi.nlm.nih.gov/pubmed/12828390

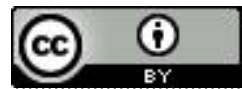




\title{
Lower socioeconomic status among men in relation to the association between job strain and blood pressure
}

\author{
by Paul A Landsbergis, PhD, ${ }^{1,2}$ Peter L Schnall, MD, ${ }^{3}$ Thomas G Pickering, MD, ${ }^{2}$ Katherine Warren, $B A,{ }^{2}$ \\ Joseph E Schwartz, $P h D^{4}$
}

\begin{abstract}
Landsbergis PA, Schnall PL, Pickering TG, Warren K, Schwartz JE. Lower socioeconomic status among men in relation to the association between job strain and blood pressure. Scand J Work Environ Health 2003;29(3):206215.
\end{abstract}

Objectives This study attempted to determine whether the association between job strain (high job demands plus low job control) and blood pressure among men varies by socioeconomic status.

Methods The cross-sectional associations between job strain and ambulatory blood pressure, by level of education, occupational status, and income, and the interaction between job strain and these measures of socioeconomic status were assessed by multiple linear regression, adjusted for age, race or ethnicity, body mass index, alcohol use, smoking, standing position, and worksite for 283 men, aged 30-60 years, from eight worksites in New York City.

Results A substantial association between job strain and work ambulatory blood pressure was found among men with lower socioeconomic status, ranging from $2.7-11.8 \mathrm{~mm} \mathrm{Hg}$ systolic to $1.9-6.1 \mathrm{~mm} \mathrm{Hg}$ diastolic blood pressure, depending upon the measure of socioeconomic status examined. However, in the groups with high socioeconomic status, the association between job strain and ambulatory blood pressure at work was much smaller, the range in blood pressure being 0-5.3 (systolic) and $0.2-2.1$ (diastolic) $\mathrm{mm} \mathrm{Hg}$. Two of the 10 tests of the interaction between job strain and socioeconomic status had a P-value of $<0.05$.

Conclusions These data provide evidence that the relationship between job strain and blood pressure is greater among men with lower socioeconomic status.

Key terms hypertension, job stress, social class.

Job strain, defined as a combination of high psychological job demands and low job decision latitude or job control, has fairly consistently been shown to be a risk factor for cardiovascular disease, and also for blood pressure (BP) elevation when BP is measured with an ambulatory monitor $(1,2)$. Lower socioeconomic status is also consistently associated with a wide variety of disease outcomes in developed countries, including hypertension (3) and cardiovascular disease (4-6). However, synergism between low socioeconomic status and job strain has rarely been assessed.
In six studies of men (7-12) and two studies of women $(8,13)$, the associations between job strain and cardiovascular disease, in general, were stronger for employees with lower socioeconomic status. However, only two studies have examined this interaction for BP elevation. In a 1-year prospective study in Stockholm, the association between increasing job strain and increasing BP was greater for waiters than for other occupations, for example, physicians, orchestra musicians, air traffic controllers, baggage handlers, and airplane mechanics (interaction term, $\mathrm{P}=0.01$ ) (14). However,

Department of Community and Preventive Medicine, Mount Sinai School of Medicine, New York, New York, United States.

2 Division of Cardiology, Department of Medicine, Mount Sinai School of Medicine, New York, New York, United States.

3 Center for Occupational and Environmental Medicine, University of California, Irvine, California, United States.

4 Department of Psychiatry and Behavioral Science, State University of New York at Stony Brook, Stony Brook, New York, United States.

Reprint requests to: Paul Landsbergis, Department of Community and Preventive Medicine, Mount Sinai School of Medicine, Box 1043, One Gustave L Levy Place, New York, NY 10029-6574, USA. [E-mail: paul.landbergis@mssm.edu] 
among Quebec white-collar workers, women with a university degree showed a substantial association between job strain and BP, while there was no association among those without a university degree (15).

In our study, the hypothesis of an increased association between job strain and BP among employees with lower socioeconomic status was tested through an analysis of data from the Work Site Blood Pressure Study that took place in New York City (16-19).

\section{Subjects and methods}

\section{Study sample}

The Work Site Blood Pressure Study is a prospective study of psychosocial factors and ambulatory BP. It has enrolled 472 initially healthy full-time employees from a wide variety of white-collar and blue-collar job titles in New York City (16-19). This analysis focuses on the 283 eligible men participating during the first round of data collection (time 1, 1985-1988). These men were recruited from eight New York City worksites, each employing at least 150 persons. The sample selection procedures have been described in detail elsewhere (16, 17, 19). Briefly, potential subjects received casual BP screenings by specially trained staff at their worksites.

This study was initially designed as a case-referent study, before funding became available for the prospective study. After the initial screening of 3216 men at eight worksites, the subjects were eligible for selection into the initial case-referent study if they were between 30 and 60 years of age, were employed $>30$ hours a week, were able to read English, had a body mass index (BMI) of $<32.5$, had no second job of $\geq 15$ hours a week, and had been at their current worksite for at least 3 years before being approached for the study and, if applicable, before being diagnosed as having high BP (16). Potential subjects were excluded if they had a history of coronary, cerebrovascular or peripheral vascular disease, electrocardiographic evidence of myocardial infarction, ischemia or atrial fibrillation, funduscopic changes, evidence of any secondary cause of hypertension, a screening systolic BP of $>160 \mathrm{~mm} \mathrm{Hg}$, or a screening diastolic $\mathrm{BP}$ of $>105 \mathrm{~mm} \mathrm{Hg}$.

After these eligibility and exclusion criteria were applied, 1674 men were found eligible for the study, 474 cases (of mild hypertension) and 1200 referents. In order to increase the statistical power of the initial casereferent study, attempts were made to recruit all cases and a random sample of referents $(\mathrm{N}=297)$.

Eligible cases were further defined as subjects with mean casual diastolic BP of $>85 \mathrm{~mm} \mathrm{Hg}$ at both the initial screening and the recruitment (4-6 weeks later) or who were taking medication for hypertension. Those with a diastolic BP of $\leq 85 \mathrm{~mm} \mathrm{Hg}$ on both occasions and not taking antihypertensive medication were eligible to serve as referents. Workers at worksites 2 through 7 whose diastolic BP (DBP) crossed over (initial screening DBP of $>85 \mathrm{~mm} \mathrm{Hg}$ and recruitment session DBP of $\leq 85 \mathrm{~mm} \mathrm{Hg}$ or initial screening DBP of $\leq 85 \mathrm{~mm} \mathrm{Hg}$ and recruitment session DBP of $>85 \mathrm{~mm} \mathrm{Hg}$ ) were not invited to participate in the case-referent study (16). In addition, to increase the number of eligible subjects for the prospective study, beginning with the eighth site during the first round of the data collection, the following eligibility criteria were changed: (i) subjects were no longer recruited using an approximate ratio (2:3) of cases to referents as at the previous sites, (ii) subjects no longer needed to be at their worksite for 3 years but instead 1 year was enough, and (iii) the subjects who had screening and recruitment changes in their casual BP that resulted in their being classified as "crossovers" and excluded from the initial time-1 case-referent (16) and cross-sectional $(17,18)$ analyses were allowed to remain in the prospective study. The third criterion was no longer relevant to the outcome of interest (continuous measures of BP). None of these changes should have had any impact on either the effect estimates or on the validity of the findings.

After the "crossovers" and eligible screening subjects who refused participation were excluded, 84 cases and 186 referents were enrolled into the initial case-referent study. The nonparticipants in the case-referent study were slightly younger and had a slightly higher diastolic $\mathrm{BP}$ at the time of the screening than the participants had. However, there were no substantial differences between the groups in the proportion who had hypertension, systolic BP, race, education, or BMI. Thus there was little evidence to indicate any substantial bias due to the sample selection. After the addition of 13 "crossovers", 283 male participants were eligible for the cross-sectional analyses of BP at time 1.

\section{Ambulatory monitoring}

At each round of the data collection, the subjects wore an ambulatory BP monitor for 24 hours during a normal workday (16). At sites 1-7 at time 1, a SpaceLabs 5200 device (SpaceLabs Medical, Issaguah, WA, USA) was worn, and at site 8, a SpaceLabs 90202 device was worn (20). At time 1, the men currently on antihypertensive medication ( $\mathrm{N}=28$ of 283 ) were titrated off medication and then monitored for 3 weeks prior to the wearing of the ambulatory monitor. The subjects with diagnosed hypertension were eligible only if they could have their medication stopped for at least 3 weeks before they wore the ambulatory monitor and still maintain a diastolic BP of $<105 \mathrm{~mm} \mathrm{Hg}$. All 28 of the subjects on medication maintained their diastolic BP at $<105 \mathrm{~mm} \mathrm{Hg}$, and thus none were excluded for this reason. 
The monitor was attached at the subject's worksite and calibrated by comparing five successive systolic and diastolic readings against simultaneously determined auscultatory readings taken by a trained observer with a mercury column, for which the respective means both had to be within $5 \mathrm{~mm} \mathrm{Hg}$ of each other to be acceptable. The timer on the monitor was set to take readings at 15-minute intervals during the day, and 30-60 minute intervals during normal hours of sleep, and the subject was instructed to proceed through a normal workday. Each time the monitor inflated and recorded a BP during waking hours, the subject was asked to remain as motionless as possible and then to record his activity, location (work, home or sleep), position (standing, sitting, reclining), and mood in a diary. The diary information was used to compute the proportion of readings in the standing position (as a proxy measure of physical activity at work) and was used to calculate the average ambulatory BPs for each location category. When fewer than five readings were obtained at work, at home, or during sleep, the corresponding average was treated as missing data. Five readings are considered minimally sufficient to produce reliable estimates of mean work BP (21). The mean number of valid readings of the ambulatory BP at work, at home, and during sleep was 28 (SD 7), 18 (SD 7), and 13 (SD 4), respectively (19).

\section{Medical examination}

The subjects received a medical examination, which included a full history, a physical examination, a 24-hour urine collection for electrolyte excretion, and an assessment of alcohol intake, current smoking history, and exercise habits. Height and weight were determined at the physical examination, and the BMI was calculated according to the formula weight $(\mathrm{kg}) /$ height $(\mathrm{m})^{2}$.

\section{Psychosocial questionnaire}

The subjects completed a questionnaire packet, which included the Job Content Questionnaire (to evaluate job strain), the Jenkins Activity Survey, and a demographic questionnaire. The Job Content Questionnaire is a widely used, well-validated, (22) 42-item instrument based, in part, on questions drawn from the United States Quality of Employment Surveys (QES) (23, 24). All its items were scored on a Likert scale of 1 to 4 . The following value labels were used: "strongly agree", "agree", "disagree", and "strongly disagree". The following job characteristic scales were also used: job decision latitude, psychological job demands, and job-related physical exertion. Job decision latitude, an operationalization of the concept of "job control", was the sum of the following two equally weighted subscales: (i) skill utilization, measured by six items [keep learning new things, can develop skills, job requires skill, task has variety, task is repetitious (reverse scored), job requires creativity], and (ii) decision authority, measured by three items (have freedom to make decisions, can choose how to perform work, have a lot of say on the job). Psychological job demands were defined by five items (excessive work, conflicting demands, insufficient time to do work, fast work pace, hard work). Decision latitude and job demands were scaled to have a range of 12 to 48 . The internal consistency reliability (Cronbach's alpha) was 0.74 for job demands and 0.83 for job decision latitude. The 3-year test-retest reliability was $r=0.64$ for both job demands and decision latitude. Job-related physical exertion was measured by a single item (job requires lots of physical effort). Its 3-year test-retest reliability was $\mathrm{r}=0.67$.

The demographic items included gender, race or ethnicity (Caucasian, Black, Hispanic, other), and age (years). The following measures of socioeconomic status (SES) were reported at each assessment: education (years), categories of personal and family income, and job title. The response options for income were in USD 5000 increments ranging from USD 5000-9999 to USD $\geq 100000$. (The midpoint of each income category was used for computing the sample means.) The participants' job titles were coded with a 3-digit occupational code using the 1980 Standard Occupational Classification (SOC) system (25). The codes were classified as whitecollar (managerial and professional specialty occupations, SOC 003-199), clerical-technical (technical, sales and administrative support occupations, SOC 203-389), or blue-collar (service; precision production, craft and repair occupations; operators, fabricators and laborers, SOC 403-472, 503-889) on the basis of Census Bureau categories. Each participant was also assigned an occupational status score for his occupation code on the basis of the system developed by Nam \& Terrie (26). These status scores can range from 0 to 100 (with a median of 50) and are based on the median educational and income level of persons counted in the United States Census according to their occupation code. Over 3 years, the measures of SES displayed high test-retest reliability: education $(\mathrm{r}=0.99)$, occupational status $(\mathrm{r}=0.92)$, personal income $(\mathrm{r}=0.84)$, and family income $(\mathrm{r}=0.82)$.

The 52-item Jenkins Activity Survey (27) was administered to evaluate type-A behavior, and the subjects were classified as "type A" if they scored above zero. The 3-year test-retest reliability was 0.70 (kappa) or 0.72 (phi coefficient).

Alcohol and smoking behavior was assessed by a questionnaire at the time of the medical examination, with the responses reviewed by a nurse. Following the widely used survey of Cahalan et al (28), alcohol consumption was based on two questions representing frequency and quantity. First, the subjects indicated how 
often they took a drink of beer, wine, or liquor. Second, they reported how many alcoholic beverages they typically had per occasion. Regular drinking was defined as binge drinking or drinking $\geq 4-6$ days/week. The 3year test-retest reliability was 0.40 (phi coefficient). Current smoking was based on one question ("Do you smoke cigarettes?"; yes, no), and it was treated as a dichotomous measure. The 3-year test-retest reliability was 0.69 (both the kappa and phi coefficients).

\section{Construction of the job-strain exposure variable}

The interaction between psychological job demands and job decision latitude, which defines job strain, was modeled with the use of the previously reported job-strain "quadrant" term $(16,17,22)$. This term is computed by dichotomizing demands and latitude at their respective sample medians for males. The dichotomous job-strain variable was defined as job decision latitude $<37$, as well as job demands $>32$. Despite the relative stability of both continuous subscales, job strain is unstable over 3 years (kappa 0.27 , phi coefficient 0.29 ).

\section{Data analysis}

To estimate the magnitude of interaction, we computed six-level categorical variables for the combination of job strain and each variable of SES. The dichotomous jobstrain variable was multiplied with the natural categories of education ( $\leq 12$ years, $13-15$ years, $\geq 16$ years) and occupational status (blue-collar, clerical-technical, white-collar) and approximate tertiles of income and continuous occupational status. The reference group was the one with the least hypothesized association with BP (ie, no job strain and high SES). The outcome variables were work, home, and sleep ambulatory systolic and diastolic BP at time 1. The analyses were conducted using multiple linear regression controlling for age (years), race or ethnicity (Caucasian, Black, Hispanic, other), BMI, current smoking status (yes,no), regular alcohol drinker (yes,no), proportion of ambulatory BP readings in the standing position, and worksite. The analyses of systolic BP also controlled for the quadratic term of age. An addition of other potential confounders (job-related physical exertion, type-A behavior, and urine sodium excretion) to the regression models produced only slight changes in the coefficients of the job strain-SES regression, and therefore these variables were not included as covariates in the final model.

The statistical significance of the hypothesized interaction was assessed by computing two dummy variables for each trichotomized SES variable, multiplying the dummy variables with job strain, adding the two product terms to the model with the main effects, and examining the F-statistic for the change in $\mathrm{R}^{2}$.

\section{Missing data}

There were very few missing data for the subjects included in these analyses. There were no missing data on job strain, education, or job title (and therefore occupational status). The 5 men missing personal income data and 11 men missing family income data were excluded from the analysis of these measures. Those missing data on ambulatory BP were excluded from the analyses of that measure. The modal category (or mean) was substituted for the few pieces of missing data on the categorical (or continuous) covariates.

\section{Sample demographics}

The sample of 283 men averaged 14.3 (range 6-18) years for education, USD 50629 for personal income, USD 58667 for family income (range for both personal and family income being USD $17500-\geq 100000$ ), and 72.0 (range 15-95) for occupational status. The men were predominantly white-collar (46\% of sample), but also included a variety of clerical-technical (33\%) and blue-collar (21\%) jobs (tables 1 and 2). As in United States national studies (29), positive correlations were observed between SES and both job decision latitude $(\mathrm{r}=0.36-0.44)$ and job demands $(\mathrm{r}=0.28-0.36)$. As a result, our measure of high demand-low latitude work ("job strain") was not significantly associated with any measure of SES (tables 1 and 2). Job strain was also not significantly associated with any potential confounder or other variable in tables 1 and 2. In fact, the nonsignificant tendency was for men with job strain to have lower values of risk factors such as age, blue-collar job, smoking, and alcohol use.

None of the measures of SES were significantly associated with ambulatory BP at work. Most were near the null value. The largest association was for blue-collar men, whose systolic BP at work was $4.0 \mathrm{~mm} \mathrm{Hg}$ [95\% confidence interval (95\% CI) $-2.4-10.3$ ] higher than that of the white-collar men. Type-A behavior was associated with higher SES; thus type-A behavior could not explain the higher BP in the job strain groups with low SES.

\section{Results}

The associations between job strain and ambulatory BP at work tended to be larger among the men with lower education and occupational status (table 3). For example, blue-collar men with job strain had an adjusted mean systolic BP that was 11.8 (95\% CI 1.6-22.0) mm $\mathrm{Hg}$ higher than that of the white-collar men without job strain and $8.4 \mathrm{~mm} \mathrm{Hg}$ higher than that of the white-collar men with job strain. Men with only a high-school education with job strain had an adjusted systolic BP 
Table 1. Means and standard deviations for the age, body mass index (BMI), 24-hour sodium level, education, occupational status, personal income, family income, and physical exertion at work for the 283 male employees, aged 30-60 years, who participated in the study from eight worksites in New York City by category of job strain. ${ }^{\text {a }}$

\begin{tabular}{lccccc}
\hline & \multicolumn{4}{c}{ Category } \\
\cline { 2 - 3 } Characteristic & Job strain (N=61) & & No job strain (N=222) \\
\cline { 2 - 3 } \cline { 5 - 6 } & Mean & SD & & Mean & SD \\
\cline { 2 - 3 } & & & & & \\
\hline Age (years) & 42.9 & 8.8 & & 44.6 & 8.6 \\
Body mass index (kg/m²) & 25.8 & 3.2 & & 25.7 & 2.7 \\
24-hour urine sodium & 142.5 & 56.2 & & 150.6 & 66.5 \\
(mEq/24 hours) & & & & & \\
Education (years) & 14.4 & 2.5 & & 14.3 & 2.4 \\
Occupational status b & 74.2 & 18.7 & & 71.4 & 18.4 \\
Personal income (USD) & 48051 & 20209 & 51324 & 22878 \\
Family income (USD) & 56293 & 22411 & 59311 & 23468 \\
Physical exertion at work & 1.85 & 0.9 & 1.85 & 0.8 \\
\hline
\end{tabular}

a All 283 employees were included in all the comparisons, except for personal income $(\mathrm{N}=278)$, family income $(\mathrm{N}=272)$, home blood pressure $(\mathrm{N}=277)$, and sleep blood pressure $(\mathrm{N}=253)$ due to missing data.

${ }^{b}$ Nam-Terrie scale: status scores could range from 0 to 100 (with a median of 50) and were based on the median educational and income level of persons counted in the 1980 United States census according to their occupational code.

Table 2. Percentage of the 283 subjects who were white-collar, clerical, and blue-collar workers, were regular alcohol drinkers, had some college education, had type-A behavior, were Caucasian, were current smokers, and had Ambulatory blood pressure readings at work in the standing position, by categry of job strain.

\begin{tabular}{lll}
\hline \multirow{3}{*}{ Characteristic } & \multicolumn{2}{c}{ Category } \\
\cline { 2 - 3 } & $\begin{array}{l}\text { Job strain } \\
(\mathrm{N}=61)\end{array}$ & $\begin{array}{l}\text { No job strain } \\
(\mathrm{N}=222)\end{array}$ \\
\cline { 2 - 3 } & $\frac{\%}{\%}$ \\
\hline
\end{tabular}

Occupation

White-collar

Clerical, technical, administrative

Blue-collar

Regular alcohol drinker

Some college education

Type-A behavior

Caucasian

Current smoker

Work ambulatory blood pressure readings

in standing position

that was $6.5(95 \% \mathrm{CI}-0.7-13.7) \mathrm{mm} \mathrm{Hg}$ higher than that of college graduates without job strain and $3.8 \mathrm{~mm}$ $\mathrm{Hg}$ higher than that of college graduates with job strain. In general, the high-status groups tended to show little or no association between job strain and BP, a pattern that was the most consistent for diastolic BP.

The hypothesized pattern of interaction was somewhat less consistent for income (table 3). For systolic $\mathrm{BP}$, there was a tendency for the greatest association between job strain and BP to occur among the men in the middle-income category. The men in the lowest personal income category were, in fact, $86 \%$ white-collar and only $2 \%$ blue-collar, $74 \%$ having a college degree. (A similar pattern was observed for the family income categories.) The blue-collar workers in this sample tended to be skilled workers with income in the middle and upper tertiles of the distribution.

Two of the ten tests of interaction between job strain and SES had a P-value of $<0.05$. The patterns of association for home and sleep ambulatory BP were slightly less consistent than those of the ambulatory BP at work (data not shown).

The interaction between the components of job strain (demands and latitude) and SES was also examined for their association with BP. None of the P-values for the interaction terms for demands or latitude were below 0.05 , and only two were below 0.15 (data not shown). Most of the P-values for the interaction terms were higher than those for job strain and SES. Thus it appears that the formulation of job strain-SES best specifies the interaction associated with higher BP. In addition, the pattern of interaction (a dose-response effect of the work stressor by SES level) was somewhat more consistent for job strain than for job demands.

\section{Discussion}

We found a substantial association between job strain and BP at work among men with lower SES, the BP ranges being 3-12 (systolic) and 2-6 (diastolic) $\mathrm{mm} \mathrm{Hg}$. In contrast, in the groups with high SES, the association between job strain and BP at work was, for the most part, near the null value. While there was some inconsistency in the pattern of findings for income (perhaps due to the higher income of blue-collar workers in this sample), workers with a personal income of USD 50000 or greater or a family income of USD 60000 or greater showed little or no association between job strain and BP. Among the men exposed to job strain, there was a clear inverse dose-response relationship between most of the measures of SES and BP. Therefore, these data provide evidence that the relationship between job strain and BP among men varies by SES. It remains to be determined whether such synergism exists for women.

The association between job strain and BP at work at time 1 among the men with lower SES was clinically significant and substantial, roughly 1-2 times the difference between Blacks and Caucasians in this sample and similar to the estimated effect of aging 15-30 years or gaining 25-50 pounds (11-23 kilograms) in weight.

If the findings are confirmed, they identify a subset of employed men who are substantially more likely to be hypertensive than the general population. In this sample, the high-risk group was relatively small (ie, only $6 \%$ 
Table 3. Association between job strain and work ambulatory blood pressure of 282 male employees aged 30-60 years in eight worksites in New York City, by level of socioeconomic status (SES), as adjusted for age, race or ethnicity, body mass index, alcohol use, smoking, standing position, and worksite. ${ }^{\mathrm{a}}$

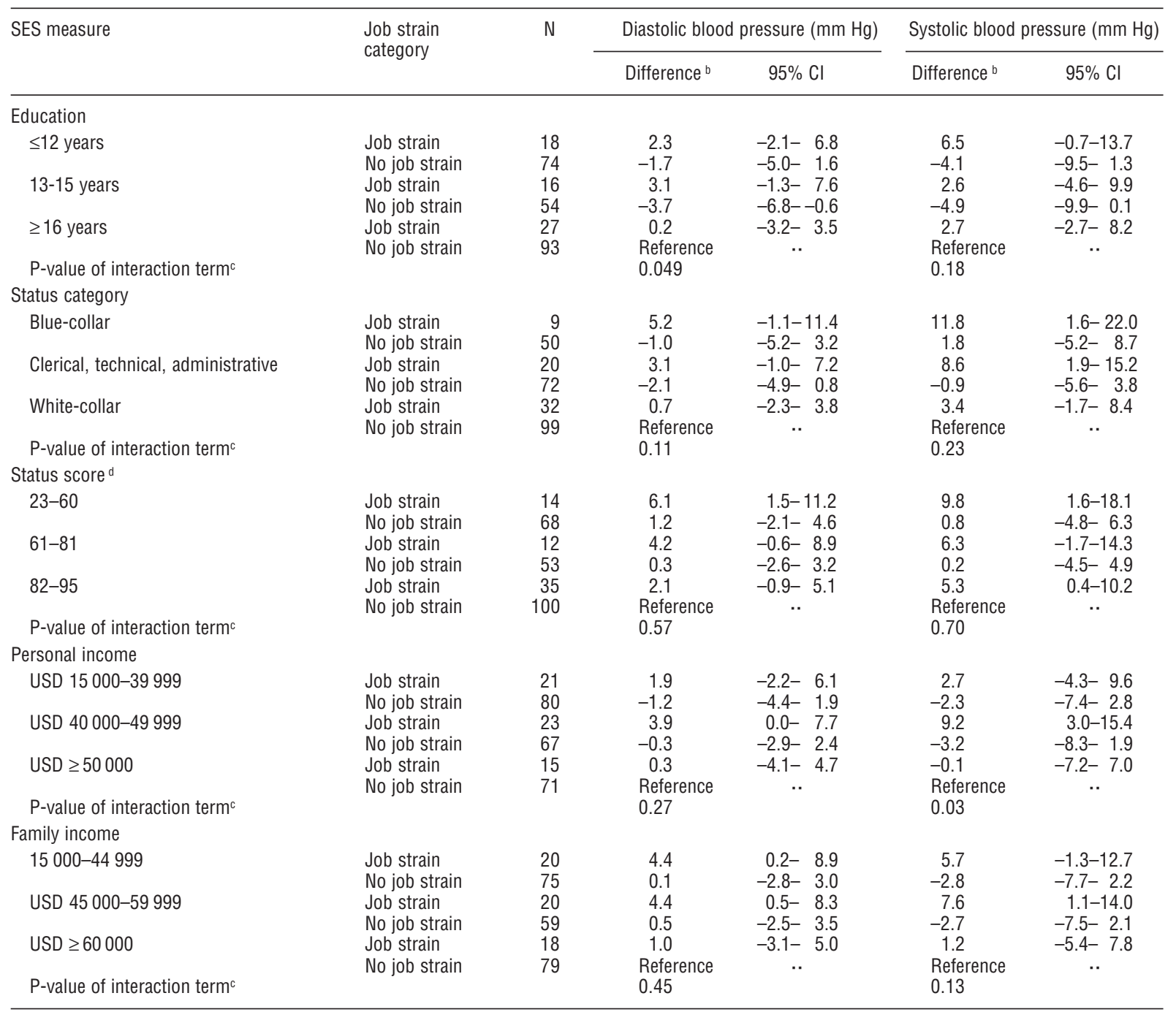

a The number was 282 for all the comparisons, except for personal income ( $N=277)$ and family income $(\mathrm{N}=271)$. One person with $<5$ ambulatory blood pressure readings at work was excluded from the blood pressure analysis.

${ }^{\mathrm{b}}$ Difference from reference group in adjusted mean BP.

c The P-value of the interaction term was computed by multiplying job strain by a trichotomous measure of the SES variable.

d Nam-Terrie scale: status scores could range from 0 to 100 (with a median of 50) and were based on the median educational and income level of persons counted in the 1980 United States census according to their occupational code.

had both job-strain exposure and no college education and only $10 \%$ had both job-strain exposure and a bluecollar or clerical-technical job). This small size was due, in part, to the difficulties in recruiting industrial and assembly-line workers at large workplaces in New York, a city with few large factories (16). Some blue-collar occupations (eg, taxi or bus driver, waiter, police officer, firefighter) were excluded since vigorous arm movement interferes with the proper functioning of an ambulatory monitor. Therefore, the high-risk group was likely to be larger in size in the United States population as a whole. In the United States, in 1990, 50.5\% of the active male labor force was in blue-collar jobs and $21.3 \%$ was in clerical-technical jobs (30) versus $21.2 \%$ and $32.5 \%$, respectively, in this sample. Similarly, in the United States, in 1990, $48.9 \%$ of men had no more than a high-school education (30) versus $32.5 \%$ in this sample.

\section{Effects of the study design on the findings}

This study was designed to minimize potential selection bias that may artificially inflate associations. To reduce the likelihood that hypertensives may be selected into high-strain jobs, we required that cases be at their worksite at least 3 years before diagnosis. In addition, there 
was no association between case-referent status (or mean BP) and personality or psychological measures such as anxiety, hostility, anger, type-A behavior, or negative affectivity, which might have influenced job selection $(16,31)$. In fact, in national studies, the opposite pattern is seen-people tend to select out of highstrain jobs over time (32).

On the other hand, restrictions to the range of variation in exposure and outcome due to the study design may have reduced the precision of the estimates of the main effects of job strain and SES and may have affected the patterns of interaction. Blue-collar and high-strain jobs may have been underrepresented in this sample, and non-English speakers (eg, those working in "sweatshops") were excluded. Participants with a screening BP of $>160 / 105 \mathrm{~mm} \mathrm{Hg}$ were also excluded, due both to ethical reasons (the risks of coming off antihypertensive medication while wearing the ambulatory monitor), and the hypothesis that stress mechanisms (eg, sympathetic hyperactivity) would have little additional effect at these levels (33). Finally, potential subjects with cardiovascular disease were excluded since BP is typically lower following a heart attack or stroke (34) and those with documented target organ damage may self-select out of high-strain jobs. Unless the study participants were selected on the basis of both hypertension and job strain (which seems implausible), the exclusions were unlikely to have affected our results.

The validity of the findings is enhanced by the use of the state-of-the-art technique of measuring BP-ambulatory monitoring, which is more reliable and more valid than recording BP in a clinical setting (20). Standard, highly reliable measures of exposure to job strain and SES were also utilized. The Job Content Questionnaire (23) has been widely used in studies of job characteristics and cardiovascular disease $(1,2)$. This questionnaire, in contrast to some job stress questionnaires, does not ask about perceptions of stress (eg, "how stressed do you feel by..."), rather inquires about objective job characteristics, such as the extent of one's decision-making authority. Several studies employing expert ratings have found high correlations $(r>0.6)$ with self-report measures of job decision latitude $(7,35,36)$. National surveys in the United States have shown high proportions of between-occupation variance in self-reported job decision latitude and valid patterns of response (eg, much higher self-reported latitude for managers as compared with that of assembly-line workers) (29).

However, the potential remains for self-reported exposure to overestimate associations, particularly for psychological job demands, an inherently more subjective measure than decision latitude. The subjects were not aware of their ambulatory BP recorded at time 1 when they completed the questionnaire, although some were aware of a previous diagnosis of hypertension.
However, there is little evidence that the cases exaggerated their job demands. Job demands were not associated with case-referent status (16), or with mean diastolic BP, only with systolic BP at work (18). If the cases exaggerated their responsibility and authority levels (decision latitude) due to the prevailing popular belief in "executive stress", then the cases would have underreported job strain, and the association between job strain and BP would have been underestimated. Finally, there was also no association between case-referent status (or mean BP) and personality or the psychological measures that may have influenced reporting $(16,31)$.

\section{Interaction between job strain and socioeconomic status}

Further research is needed to understand the mechanisms explaining the synergism between job strain and lower SES in their association with BP. Several hypothesized mechanisms, such as increased levels of smoking, BMI, or job-related physical exertion among workers with lower SES, are not supported by the current study, since these risk factors were controlled in the analyses. Only one worksite contained evening or nightshift workers, and worksite was controlled in the analyses. However, the evening and nightshift workers had a lower SES than the dayshift workers. Thus shift work needs to be evaluated as one potential mechanism for the combined impact of job strain and low SES on BP.

In addition, workers with a lower SES face many other hazards that may interact with job strain, including cardiotoxic chemicals, physical stressors such as noise $(37,38)$, other psychosocial workplace stressors such as effort-reward imbalance (39), threat-avoidant vigilant work (40) or job insecurity, life stressors such as unemployment, crime, a "deteriorating urban physical and social environment" (37, p 247), social isolation (41), economic rewards that are low (42) and decreasing (43), psychological effects of such stressors (eg, hostility) (44, 45), depression (46), "learned helplessness" (47), lack of "active emotional coping" (48), unhealthy behavior (eg, sedentary behavior), and poorer biological conditions (eg, higher levels of fibrinogen) $(49,50)$.

In addition, the "broadly serviceable resources" (eg, money, knowledge, power, prestige, social support, social network) available to a person with a higher SES (51, p 87) may buffer the impact of job strain on the cardiovascular system. For example, persons with a higher SES have greater access to exercise facilities (52), better housing, nutrition (53), and medical care (54), greater workplace social support and social networks (41), and greater coping resources, such as hopefulness, planning, a sense of control (50), mastery, selfefficacy (49) and active learning (55).

Two alternative explanations for the observed interaction include measurement invalidity and construct 
invalidity. First, while there is evidence of the validity of self-report measures of job decision latitude (7, 29, 36 ), job demands are inherently more subjective. Measures of demands may be too nonspecific with regard to white-collar workers, and the concept of demands may be too loosely defined (11) to capture "high performance demands and an internalized work ethic" (37, p 265). Thus the absence of an association between job strain and BP among workers with a high SES may be due to the limited validity of the Job Content Questionnaire in this group. Other instruments, such as the effort-reward imbalance questionnaire (39), may be needed to capture such demands better. However, since the error variance of the job demands (and job decision latitude) scale did not significantly differ across the strata of education (data not shown), there is no evidence that the participants with a high SES found the scale items less appropriate than did those with a low SES.

Second, while the job demands-control construct has two main hypotheses (22) - strain and activity levelonly the strain hypothesis has typically been tested in studies on cardiovascular disease. The strain hypothesis predicts that the combination of high demands and low control ("job strain") increases stress and the risk of stress-related illnesses such as hypertension and cardiovascular disease $(1,2)$. However, the activity hypothesis predicts that job characteristics influence motivation and behavior. For example, low control-low demand situations ("passive" jobs) can result in reduced ability to solve problems or tackle challenges $(22,56)$ and feelings of depression (56). Conversely, when high job demands are matched with greater job decision latitude (controllable stressors or "active" jobs), more active learning occurs and people can develop a broader range of coping strategies (22), including possibly healthier behavior. Therefore, even though employees with a higher SES may face situations of job strain (job demands greater than job control), they will also, in their careers, probably have experienced "active" (high demand-high control) work and the psychological and behavioral benefits such jobs provide. "Active" work has been associated with a reduced risk of cardiovascular disease in some studies $(57,58)$. However, men in "active" jobs did not have a reduced risk of mild hypertension in this sample (17), and the interaction between job strain and SES was observed even after control for some types of health behavior. Therefore, the current data do not provide strong support for this alternative hypothesis.

\section{Economic and workplace trends}

Current economic and workplace trends associated with economic globalization appear to be having dramatic interrelated effects on job strain, SES patterns, and the health of groups with lower SES (59-62). In the United
States, real income declined for the bottom two-thirds of the population between 1979 and 1993 (63) and therefore contributed to the highest levels of income inequality in the past 60 years $(64,65)$. Strong effects of income inequality on various health outcomes, including cardiovascular disease, have been observed $(63,66,67)$.

Concurrently, work conditions are deteriorating. Trends such as downsizing, outsourcing to low-wage suppliers, increases in contingent and temporary work, and new management systems such as "lean production" appear to be intensifying work (68) and increasing the prevalence of job strain. The United States now leads the industrialized world in workhours per year per worker (69). In Europe, the prevalence of job strain increased from 25\% to 30\% between 1991 and 1996 (70). Finally, the proportion of United States employees belonging to labor unions has declined sharply over the past 40 years, a situation that is weakening an important source of influence over work conditions and the buffer to job stress available to employees with a lower SES (71). "Among many manual and service sector employees when individual-level control over one's task or one's career is limited, social or collective alliances become vitally important ...., a culture of solidarity ...., a strategy for surviving on the job ...." (37, p 261).

These trends may be contributing to the increasing inverse association between SES and cardiovascular disease $(62,72,73)$. Synergism between job strain and low SES in their effect on BP and cardiovascular disease, if confirmed, would be one intervening mechanism explaining this increasing gradient and would imply the need for greater prevention efforts, such as healthy job redesign, among workers with a lower SES.

\section{Acknowledgments}

This research was supported by grants HL18232, HL30605, HL47540, and HL55165 from the National Heart, Lung and Blood Institute, Bethesda, Maryland, and the analyses were conducted by the first author as part of his doctoral dissertation at the Columbia University Mailman School of Public Health. He is grateful to his committee, Ana Diez-Roux, Bruce Link, Sharon Schwartz, Jeanne Stellman, and Joseph Schwartz for their support and their helpful comments on an earlier draft of this manuscript.

\section{References}

1. Schnall PL, Landsbergis PA, Baker D. Job strain and cardiovascular disease. Ann Rev Public Health 1994;15:381-411.

2. Belkic K, Landsbergis PA, Schnall P, Baker D, Theorell T, Siegrist J, et al. Psychosocial factors: review of the empirical 
data among men. In: Schnall P, Belkic K, Landsbergis PA, Baker De, editors. The workplace and cardiovascular disease. Philadelphia (PA): Hanley and Belfus; 2000. p 24-46. Occupational medicine: state of the art reviews, vol 15.

3. Colhoun HM, Hemingway H, Poulter NR. Socio-economic status and blood pressure: an overview analysis. J Hum Hypertens 1998;12:91-110.

4. Marmot MG, Smith DG, Stansfeld S, Patel C, North F, Head $\mathrm{J}$, et al. Health inequalities among British civil servants: the Whitehall II study. Lancet 1991;337:1387-93.

5. Kaplan GA, Keil JE. Socioeconomic factors and cardiovascular disease: a review of the literature. Circulation 1993;88(4 Pt 1):1973-98.

6. Kunst AE, Groenhof F, Andersen O, Borgan J-K, Costa G, Desplanques G, et al. Occupational class and ischemic heart disease mortality in the United States and 11 European countries. Am J Public Health 1999;89:47-53.

7. Karasek R, Baker D, Marxer F, Ahlbom A, Theorell T. Job decision latitude, job demands, and cardiovascular disease: a prospective study of Swedish men. Am J Public Health 1981; 71(7):694-705.

8. Johnson JV, Hall EM. Job strain, workplace social support, and cardiovascular disease: a cross-sectional study of a random sample of the Swedish working population. Am J Public Health 1988;78(10):1336-42.

9. Johnson JV, Hall EM, Theorell T. Combined effects of job strain and social isolation on cardiovascular disease morbidity and mortality in a random sample of the Swedish male working population. Scand J Work Environ Health 1989;15(4):2719.

10. Theorell T, Tsutsumi A, Hallqvist J, Reuterwall C, Hogstedt $\mathrm{C}$, Fredlund P, et al. Decision latitude, job strain and myocardical infarction: a study of working men in Stockholm. Am J Public Health 1998;88:382-8.

11. Hallqvist J, Diderichsen F, Theorell T, Reuterwall C, Ahlbom A, The SHEEP Study Group. Is the effect of job strain on myocardial infarction due to interaction between high psychological demands and low decision latitude? Results from Stockholm heart epidemiology program (SHEEP). Soc Sci Med 1998;46(11):1405-15.

12. Hammar M, Alfredsson L, Theorell T. Job characteristics and the incidence of myocardial infarction: a study of men and women in Sweden, with particular reference to job strain. Int J Epidemiol 1994;23(2):277-84.

13. LaCroix AZ. High demands/low control work and the incidence of CHD in the Framingham cohort [dissertation]. Chapel Hill (NC): University of North Carolina; 1984.

14. Theorell T, Perski A, Åkerstedt T, Sigala F, Ahlberg-Hulten $\mathrm{G}$, Svensson J, et al. Changes in job strain in relation to changes in physiological states: a longitudinal study. Scand J Work Environ Health 1988;14:189-96.

15. Laflamme N, Brisson C, Moisan J, Milot A, Mâsse B, Vézina M. Job strain and ambulatory blood pressure among female white-collar workers. Scand J Work Environ Health 1998; 24(5):334-43.

16. Schnall PL, Pieper C, Schwartz JE, Karasek RA, Schlussel Y, Devereux RB, et al. The relationship between "job strain", workplace diastolic blood pressure, and left ventricular mass index. Results of a case-control study J Am Med Assoc 1990;263(14):1929-35. [Published erratum appears in JAMA 1992;267(9):1209].

17. Schnall PL, Schwartz JE, Landsbergis PA, Warren K, Pickering TG. Relation between job strain, alcohol, and ambulatory blood pressure. Hypertension 1992b;19:488-94.
18. Landsbergis PA, Schnall PL, Warren K, Pickering TG, Schwartz JE. Association between ambulatory blood pressure and alternative formulations of job strain. Scand J Work Environ Health 1994;20(5):349-63.

19. Schnall PL, Landsbergis PA, Schwartz J, Warren K, Pickering TG. A longitudinal study of job strain and ambulatory blood pressure: results from a three-year follow-up. Psychosom Med 1998;60:697-706.

20. Pickering TG. Ambulatory monitoring and blood pressure variability. London: Science Press; 1991.

21. Llabre MM, Ironson GH, Spitzer SB, Gellman MD, Weidler DJ, Schneiderman N. How many blood pressure measurements are enough?: an application of generalizability theory to the study of blood pressure reliability. Psychophysiology 1988;25:97-106.

22. Karasek R, Theorell T. Healthy work: stress, productivity, and the reconstruction of working life. New York (NY): Basic Books; 1990.

23. Karasek RA, Gordon G, Pietrokovsky C, Frese M, Pieper C, Schwartz J, et al. Job content instrument: questionnaire and user's guide. Los Angeles (CA)/Lowell (MA): University of Southern California/University of Massachusetts; 1985.

24. Karasek R, Brisson C, Kawakami N, Houtman I, Bongers P, Amick B. The job content questionnaire (JCQ): an instrument for internationally comparative assessments of psychosocial job characteristics. J Occup Health Psychol 1998;3(4):322-55.

25. US Department of Commerce. Classified index of industries and occupations. Washington (DC): Bureau of the Census; 1982. Report no PHC80-R4.

26. Nam CB, Terie EW. 1980-Based Nam-Powers occupational status scores. Working paper series 88-48. Tallahassee (FL): Center for the Study of Population, Florida State University; 1988.

27. Jenkins CD, Rosenman RH, Zyzanski SJ. Prediction of clinical coronary heart disease by a test for the coronary-prone behavior pattern. New Engl J Med 1974;290:1271-5.

28. Cahalan D, Cisin IH, Crossley HM. American drinking practices: a national survey of drinking behavior and attitudes. New Brunswick (NJ): Center for Alcohol Studies; 1969.

29. Schwartz JE, Pieper C, Karasek RA. A procedure for linking psychosocial job characteristic data to health surveys. Am J Public Health 1988;78(8):904-9.

30. US Bureau of the Census. Equal Employment Opportunity File (EEO), 1990. Atlanta (GA): US Department of Commerce, Bureau of the Census; 1990.

31. Friedman R, Landsbergis PA, Schnall PL, Pieper C, Gerin W, Pickering TG, et al. Psychological variables in hypertension: relationship to casual or ambulatory blood pressure in men. Psychosom Med 2001;63:19-31.

32. Karasek RA, Theorell T, Schwartz JE, Schnall PL, Pieper CF, Michela JL. Job characteristics in relation to the prevalence of myocardial infarction in the US health examination survey (HES) and the health and nutrition examination survey (HANES). Am J Public Health 1988;78(8):910-8.

33. Julius S. Sympathetic hyperactivity and coronary risk in hypertension. Hypertension 1993;21:886-93.

34. McCall M, Elmfeldt D, Vedin A, Wilhelmsson C, Wedel H, Wilhelmsson L. Influence of a myocardial infarction on blood pressure and serum cholesterol. Acta Med Scand 1979;206: 477-81.

35. Johnson JV, Stewart WF. Measuring work organization exposure over the life course with a job-exposure matrix. Scand J Work Environ Health 1993;19:21-8.

36. Hasselhorn H, Hammar N, Alfredsson L, Westerholm P, 
Theorell T, WOLF Study Group. Differences in the impact of self-rated and externally-rated job strain on risk factors for coronary heart disease. In: Work Stress and Health: organization of work in a global economy; 1998 March 11-13. Baltimore (MD): American Psycological Association \& National Institute for Occupational Health and Safety; 1998.

37. Johnson JV, Hall EM. Class, work, and health. In: Amick B, Levine S, Tarlov A, Walsh D, editors. Society and health. New York: Oxford University Press; 1995. p 247-71.

38. Stellman J, Daum S. Work is dangerous to your health. New York (NY): Vintage; 1973.

39. Siegrist J. Adverse health effects of high-effort/low-reward conditions. J Occup Health Psychol 1996;1:27-41.

40. Belkic K, Emdad R, Theorell T. Occupational profile and cardiac risk: possible mechanisms and implications for professional drivers. Int J Occup Med Environ Health 1998;11:37-57.

41. Orth-Gomer K. International epidemiological evidence for a relationship between social supprt and cardiovascular disease. In: Shumaker S, Czajowski S, editors. Social support and cardiovascular disease. New York (NY): Plenum Press; 1994. p 97-117.

42. Lynch J, Krause N, Kaplan GA, Salonen R, Salonen JT. Workplace demands, economic reward and progression of carotid atherosclerosis. Circulation 1997;96(1):302-7.

43. US Departments of Labor and Commerce. Fact finding report. Commission on the future of worker-management relations. Washington (DC): US Departments of Labor and Commerce; 1994.

44. Scheier MF, Bridges MW. Person variables and health: personalitiy predispositions and acute psychological states as shared determinants for disease. Psychosom Med 1994;57: 255-68.

45. Haynes SG, Feinleib M. Women, work and coronary heart disease: prospective findings from the Framingham Heart Study. Am J Public Health 1980;70(2):133-41.

46. Anda R, Willianson D, Jones D, Macera C, Eaker E, Glassman A, et al. Depressed affect, hopelessness, and the risk of ischemic heart disease in a cohort of US adults. Epidemiology 1993;4(4):285-93.

47. Peterson C, Seligman M. Causal explanations as a risk factor for depression: theory and evidence. Psychol Rev 1984;91: 347-74.

48. Theorell T. Family history of hypertension-an individual trait interacting with spontaneously occuring job stressors. Scand J Work Environ Health 1990;16 Suppl 1:74-9.

49. Kubzansky LD, Berkman LF, Glass TA, Seeman TE. Is educational attainment associated with shared determinants of health in the elderly? Findings from the MacArthur studies of successful aging. Psychosom Med 1998;60(5):578-85.

50. Yen IH, Moss N. Unbundling education: a critical discussion of what education confers and how it lowers risk for disease and death. In: Adler NE, Marmot M, McEwen BS, Stewart J, editors. Socioeconomic status and health in industrial nations. Bethesda (MD): New York Academy of Sciences; 1999. p $350-1$.

51. Link BG, Phelan J. Social conditions as fundamental causes of disease. J Health Society Behav 1995; Extra issue:80-94.

52. Kawachi I, Marmot M. What can we learn from studies of occupational class and cardiovascular disease? Am J Epidemiol 1998;148:160-3.

53. Marmot M, Theorell T. Social class and cardiovascular disease: the contribution of work. In: Johnson JV, Johansson G, editors. The psychosocial work environment: work organization, democratization and health. Amityville (NY): Baywood
Publishing Company; 1991. p 33-48.

54. Hunink MG, Goldman L, Tosteson AN, Mittleman MA, Goldman PA, Williams LW. The recent decline in mortality from coronary heart disease, 1980-1990: the effect of secular trends in risk factors and treatment. J Am Med Assoc 1997;277:53542.

55. Karasek R. Lower health risk with increased job control among white collar workers. J Organ Behav 1990;11:171-85.

56. Karasek RA. Job demands, job decision latitude and mental strain: implications for job redesign. Admin Sci Q 1979;24: 285-308.

57. Steenland K, Johnson J, Nowlin S. A follow-up study of job strain and heart disease among males in the NHANES1 population. Am J Ind Med 1997;31:256-9.

58. Johnson JV, Stewart W, Hall EM, Fredlund P, Theorell T. Long-term psychosocial work environment and cardiovascular mortality among Swedish men. Am J Public Health 1996; 86(3):324-31.

59. Cooper C. Working hours and health. Work Stress 1996;10:1-4.

60. Ferrie JE, Shipley MJ, Marmot M, Stansfeld S, Smith GD. The health effects of major organisational change and job insecurity. Soc Sci Med 1998;46:243-54.

61. Tuchsen F. Working hours and ischaemic heart disease in Danish men: a 4-year cohort study of hospitalization. Int $\mathrm{J}$ Epidemiol 1993;22:215-21.

62. Tuchsen F, Endahl LA. Increasing inequality in ischaemic heart disease morbidity among employed men in Denmark 1981-1993: the need for a new preventive policy. Int J Epidemiol 1999;28:640-4.

63. Lynch J, Kaplan G, Pamuk E, Cohen R, Heck K, Balfour J, et al. Income inequality and mortality in metropolitan areas of the United States. Am J Public Health 1998;88:1074-80.

64. Weinberg D. A brief look at postwar US income inequality. Washington (DC): US Census Bureau; 1996. Current population reports, June.

65. Wolff E. Top heavy: a study of wealth inequality in America. New York (NY): Twentieth Century Fund Press; 1995.

66. McIsaac SJ, Wilkinson RG. Income distribution and causespecific mortality. Eur J Public Health 1997;7:45-53.

67. Kennedy BP, Kawachi I, Prothrow-Stith D. Income distribution and mortality: cross-sectional ecological study of the Robin Hood index in the United States. BMJ 1996;312:1004-7.

68. Landsbergis PA, Cahill J, Schnall P. The impact of lean production and related new systems of work organization on worker health. J Occup Health Psychol 1999;4(2):108-30.

69. International Labour Office. Key indicators of the labour market 1999. Geneva: International Labour Office; 1999.

70. European Foundation. Time constraints and autonomy at work in the European Union. Dublin: European Foundation for the Improvement of Living and Working Conditions; 1997.

71. Landsbergis PA, Cahill J. Labor union programs to reduce or prevent occupational stress in the United States. Int J Health Serv 1994;24:105-29.

72. Hallqvist J, Lundberg M, Diderichsen F, Ahlbom A. Socioeconomic differences in risk of myocardial infarction 19711994 in Sweden: time trends, relative risks and population attributable risks. Int J Epidemiol 1998;27:410-5.

73. Gonzalez MA, Artalejo FR, Calero JR. Relationship between socioeconomic status and ischaemic heart disease in cohort and case-control studies: 1960-1993. Int J Epidemiol 1998;27(3):350-8.

Received for publication: 9 February 2001 